\title{
É SÓ UM REAL! \\ PERFORMATIVIDADES DO COMÉRCIO INFORMAL DE ALIMENTOS NO LARGO GLÊNIO PERES EM PORTO ALEGRE
}

\author{
Viviane Vedana
}

\begin{abstract}
"Quand on étudie les relations, les postures de plusieurs êtres réels réunis dans un même espace, leurs jeux de séduction, de rejet, de povoir et ce même espace que se distribue en une avant-scène, une scène et en coulisses, le sensible est de nouveau et presque d'une manière inéluctable convoqué" Pierre Sansot
\end{abstract}

\section{Introdução}

Neste ensaio busco delinear a possibilidade de alguns cruzamentos e interlocuções entre os estudos de performance e o campo da antropologia urbana. Tratase de um ensaio, pois o foco principal de reflexão não é a interpretação de fenômenos "extraordinários" que se manifestam no meio urbano, caracterizando-se diretamente como eventos performáticos, mas sim um ponto de vista sobre práticas "ordinárias" $\mathrm{d}$ cotidiano da cidade como ações que possuem uma dimensão performática. Assim, este texto não se configura como uma análise que poderia ser considerada "clássica" ao campo da antropologia da performance, como estudos de ritual ou etnografia da fala, por exemplo, mas como uma tentativa de nuançar um estudo de antropologia urbana a partir de uma perspectiva da antropologia da performance.

O contexto etnográfico do estudo que proponho é o do mercado de rua situado no Largo Glênio Peres, chamado de Feira de Pedra, ao lado do Mercado Público de Porto Alegre. Este Largo é também chamado pelos habitantes da cidade de largo do mercado, é um espaço constituído de inúmeras interações sociais e performances, pois é habitado por artistas de rua, camelôs, vendedores ambulantes e também por habitués, ou seja, moradores do centro da cidade e mesmo de outros bairros que fazem dali um 
espaço de trocas e sociabilidades. O mercado de rua ou Feira de Pedra é um destes cenários.

Chamo de mercado de rua o conjunto dos vendedores de alimentos hortifrutigranjeiros que improvisam um espaço de vendas nos finais de tarde no Largo, produzindo uma estética peculiar na qual sons e imagens visuais são mesclados de tal forma que evidenciam as noções de descontinuidade e fragmentação da vida urbana, como apontam G. Simmel e G. Velho. No caos aparente do centro da cidade, representado principalmente no fluxo intenso de seus habitantes, a constituição deste espaço informal de vendas de alimentos apresenta certas características que podem ser melhor observadas e interpretadas tendo em vista contribuições teóricas e metodológicas dos estudos de performance. Mais especificamente refiro-me a atenção dedicada aos aspectos estéticos da situação social etnografada revelada na preocupação de muitos pesquisadores da área ${ }^{1}$ em utilizar diferentes mídias para realizar a pesquisa e reconfigurar o contexto etnográfico, além da sua tradução no próprio texto.

Em termos de uma antropologia urbana, estas práticas de comércio na rua são elementos importantes da composição estética das ruas da cidade, pois a improvisação de bancas de alimentos ao rés do chão vai conformando caminhos e criando obstáculos para os passantes desinteressados na compra. Junto com esta demarcação do espaço vem o preenchimento do lugar com sonoridades diversas, compondo uma certa melodia "nada harmoniosa" para o ambiente e, para completar, ainda somos tomados por odores característicos da mistura de poluição do trânsito com os cheiros dos alimentos. Estes são apenas alguns traços na delimitação da complexidade de elementos que dão forma a esta situação cotidiana no centro de Porto Alegre.

\section{A fluidez da urbanidade: o centro da cidade como espaço múltiplo}

Realizar uma etnografia no centro da cidade, compartilhando de seus fluxos e movimentos com outros habitantes é um desafio de relativização e de estranhamento, pois é justamente em meio a uma representação de caos e desordem que é preciso construir um distanciamento para compreender os contornos e as nuances de seus

\footnotetext{
${ }^{1}$ Ver autores como: CONQUERGOOD, D. Performance Studies: interventions and radical research. In: Bial, H. The Performnce Studies Reader. London: Routledge. BAUMAN, R. \& BRIGGS, C. Poetics and performance as critical perspectives on language and social life. In: Anual review of Anthropology, 19:5988, 1990. SULLIVAN, Lawrence. Sounds and Senses: toward a hermeneutics of performance. In: History of Religions. Chicago University Press, 1986, entre outros.
} 
micro-eventos ${ }^{2}$. Enquanto "estava lá", buscando identificar um ponto de vista a partir do qual situar-me no mercado de rua, lembrava-me de etnografias, como a de Augusto Arantes nas ruas de São Paulo e na Praça da Sé3 , e de Gilberto Velho em Copacabana, no Rio de Janeiro ${ }^{4}$. O Largo do Mercado e algumas partes do centro de Porto Alegre, de certa forma, apresentam características semelhantes com estes dois outros lugares. Pessoas de diversas classes sociais, grupos étnicos, estilos de vida e formas de habitar o mundo passam por ali. É um lugar da presença de heterogeneidades.

Para chegar até o Largo do Mercado, sigo pela Av. Borges de Medeiros, na direção bairro-centro, caminhando por esta grande via que começou a ser aberta na década de 30 e foi finalizada em meados da década de 40, para resolver os problemas de circulação no centro de Porto Alegre. Nesta caminhada, insiro-me no fluxo intenso de pessoas de um final de tarde da metrópole, momento em que muitas pessoas cruzam a cidade indo e vindo no trajeto trabalho - casa, casa - escola/faculdade; filas para os ônibus que vão a várias localidades e bairros, carros e táxis num tráfego intenso. Nas calçadas o comércio comunica suas possibilidades aos transeuntes: de um lado os bares e lancherias com seus sucos e pastéis, algumas "máquinas de sorvete italiano" na porta, lojas de roupas e outras quinquilharias em meio aos bares. Do outro lado, nas proximidades do meio-fio, o "comércio informal", bancas de frutas, vendedores ambulantes de pilhas, isqueiros, relógios, meninas distribuindo propagandas de consórcio ou seguro, bancas de cachorro quente e outras de balas, chocolates e bolachas, todas ocupando o espaço da rua, todos anunciando os produtos a venda e seus preços. Estas são as características do caminho que sigo até chegar ao Largo Glênio Peres, ou Largo do Mercado onde alguns vendedores começam a organizar suas vendas.

A condição de uma experiência estética do urbano, no entanto, se evidencia pelo som: enquanto caminho pela Avenida Borges de Medeiros que segue até o largo, ouço vendedores de vale transporte (passagens de ônibus), que balançam os saquinhos com as fichas fazendo um chicchicc e gritando sem parar, VTVTVTVT... ou então VALEVALEVALEVALE... VENDOVALE... O som me acompanha até o final da avenida, é claro que misturado com muitos outros, como o de veículos, músicas vindas

\footnotetext{
${ }^{2}$ MOLES, Abraham e RHOMER, Elisabeth. Labyrinthes du Vécu. L'espace: matière d'actions. Paris, Librairie des Meridiens, 1982.

3 ARANTES, Antônio A. Paisagens Paulistanas: transformações do espaço público. Campinas, SP:Editora da Unicamp: São Paulo: Imprensa Oficial, 2000.

${ }^{4}$ VELHO, Gilberto. Projeto e Metamorfose : antropologia das sociedades complexas. Rio de janeiro, Ed. Jorge Zahar, 1999.
} 
de algumas lojas, conversas das pessoas que vão passando. Impossível não fazer referência a poétique de la ville de Pierre Sansot (1988) e a especificidade que atribui ao termo "urbano", o qual aplica-se a determinados objetos que são essencialmente produzidos e consumidos nas cidades antes de espalharem-se por todo lugar, "além do uso, esses objetos implicam valores implícitos que ultrapassam a utilidade e que subentendem um estilo de vida: aquele mesmo das cidades". 5 São estes objetos urbanos, que constituem um sentido poético para a cidade. Como objetos estou pensando a diversidade de comércio, as bugigangas vendidas nas bancas de camelôs, os VTs, enfim, as coisas que se relacionam com a dinâmica da vida cotidiana da cidade.

Conduzida por estes sons da cidade que me aproximo do Largo. Avisto primeiro o prédio da Prefeitura, antigo, bonito, com cores fortes. Do outro lado da rua está o Mercado Público, mas ainda não enxergo o Largo em função do prédio de um shopping de fábrica que fica numa das esquinas. Caminhando mais um pouco alcanço o Largo Glênio Peres, ele é muito grande, mas o movimento de pessoas se concentra próximo ao mercado.

\section{A construção cênica do espaço da venda}

Pensar a construção cênica do espaço da venda neste mercado de rua é também articular uma idéia de experiência estética da cidade que pode ser vivida de diferentes formas por seus habitantes. O que estou chamando aqui de experiência estética tem como base às diversas formas de expressão e comunicação que são acionadas no espaço

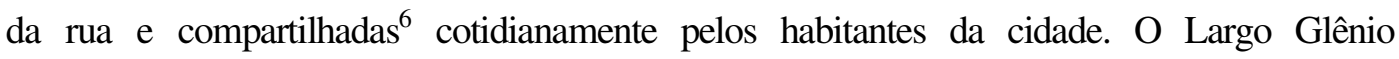
Peres é um espaço privilegiado de performatividades e micro-eventos, apresentando-se como um amplo espaço aberto, retangular, que possibilita sua ocupação por diversos tipos de atividades que se caracterizam pela aglomeração de pessoas com intensa conformação e desconfiguração de micro-eventos. São vendedores ambulantes de diversos tipos e com as mais diversas mercadorias (vale transporte, isqueiros, pilhas, antenas, venenos para insetos, prendedores de cabelo, e inúmeras quinquilharias que se possa imaginar), pastores de igrejas, profetas e pregadores que lêem suas orações e

\footnotetext{
5 SANSOT, Pierre. Poétique de la Ville. Paris, Meridiens Klincksiek, 1988. p. 387

6 Refiro-me aqui principalmente ao trabalho de KAPFERER, Bruce. Performance and the structuring of meaning and experience. In: Anthropology of Experience. Turner, V. \& Bruner, E. eds. Chicago: University of Illinois Press, 1986.
} 
fazem suas preces em meio a um crescente circulo de pessoas que vai se formando e transformando a sua volta, performers os mais diversos, engolidores de fogo, homens que desenvolvem habilidades corporais "estranhas" e se apresentam por algum trocado no meio da rua. Em meio a esta diversidade ainda temos os passantes, pedestres habitantes da cidade, que atravessam o largo para irem aos mais diferentes lugares. Partindo desta descrição é que começa a se delinear a noção de uma experiência estética compartilhada de cidade, pois é na composição e participação - ou mesmo na observação curiosa - destes micro-eventos que vão se constituindo os sentidos para uma urbanidade. Viver na cidade, transitar por seus diferentes erritórios é compartilhar desta experiência de diversidade cultural.

A aparente aleatoriedade destas apresentações parece afastar-se da concepção usual de ritual, onde se prevê uma ordenação dos eventos e dos fatos para então se chegar à possibilidade de construção de um sentido comum para a vida social e de mudança. Assim, cada um destes "espetáculos" poderia ser analisado de forma independente do outro, chegando-se então a afirmação de uma estrutura performática onde os atores e platéia apresentariam suas delimitações mais rígidas. Porém, tendo em vista o caráter de movência ${ }^{7}$ da própria performance e ensaiando um olhar sobre estes eventos que leve em conta a dimensão de conformação do espaço urbano é que a concepção de uma experiência estética da cidade torna-se mais palpável. Neste caso, estas formas de atuar no espaço da rua, seja com as vendas, seja na pregação dos pastores, ganha uma dimensão de expressividade das diversidades culturais a partir das quais a vida urbana é composta. É neste sentido que podemos pensar o largo do mercado como um espaço cênico no âmbito da vida urbana de Porto Alegre.

Faço estas observações porque o próprio espaço do mercado de rua que tomei como objeto deste ensaio não assume uma conformação mais delimitada, onde é possível distinguir claramente os lugares de vendedor e comprador, bem como de passantes. É importante colocar que a experiência de uma etnografia no mercado de rua do Largo Glênio Peres está permeada das imagens da Feira-Livre da Epatur, local onde se deu a etnografia de minha dissertação de mestrado sobre as práticas cotidianas de

\footnotetext{
${ }^{7}$ Morris, Rosalind. All made up: performance theory and the new anthropology of sex and gender. IN: Annual Review of Anthropology, 1995. BUTLER, Judith. Performative acts and gender constitutions: an essay in phenomenology and feminist theory. In: Bial, H. The Performnce Studies Reader. London: Routledge.
} 
fregueses e feirantes ${ }^{8}$. Nesta pesquisa anterior havia certas conformações das relações entre estes atores, bem como na configuração do espaço que não se encontram no mercado de rua do largo do mercado, a diferente denominação já institui estas diferenças.

É claro que a diferença principal é o fato de que a Feira-Livre da Epatur é um lugar institucionalizado de vendas de alimentos enquanto que no largo do mercado as vendas se dão informalmente ${ }^{9}$. Isso vai definir muitos elementos na conformação estética do espaço bem como nas interações entre vendedores e compradores. Começando pela formação das bancas de alimentos, que na verdade parecem mais "tabuleiros"10 de vendas, já é possível identificar um caráter de improvisação. Os vendedores montam seu espaço de vendas em cima de algumas caixas de madeira, geralmente as caixas que abrigam frutas e outros hortifrutigranjeiros, como podemos ver nos supermercados, por exemplo. Em cima destas caixas são apoiadas tábuas também de madeira que variam desde tapumes de obras de construção civil até pedaços de portas ou coisas do gênero. Sobre tudo isso estão os alimentos. Dado o caráter informal destas vendas, a constituição destas bancas improvisadas tem um significado/função bastante específico: a facilidade com a qual podem ser desmanchadas caso ocorra algum tipo de fiscalização da prefeitura.

Estes tabuleiros acabam sendo dispostos na forma de uma fila, uns ao lado de outros, alguns quase grudados, formando uma grande "mesa" que se estende ao lado do Mercado Público, há uma distância de mais ou menos três metros deste. Mas a grande diferença em relação à feira-livre se dá em termos da flanerie, ou seja, da possibilidade de um passeio onde se observa calmamente os produtos a serem consumidos, trava-se alguma conversa com o vendedor ou algum outro consumidor. As categorias que tenho usado aqui para designar estes atores já indicam o tipo de relação social que se estabelece: não se tratam de feirantes e fregueses, mas vendedores e consumidores - ao menos em um primeiro momento - e a interação social que vai emergir daí não se constitui pela sociabilidade característica da feira-livre. Estes são alguns aspectos a

\footnotetext{
8 "Fazer a Feira": estudo etnográfico das "artes de fazer" de feirantes e fregueses da Feira-Livre da Epatur no contexto da paisagem urbana de Porto Alegre. Orientação de Cornelia Eckert.

${ }^{9}$ Esta Feira de Pedra foi encerrada pela Secretaria Municipal de Industria e Comércio em 25 de julho de 2005, a partir de negociações com os próprios vendedores que passariam por um processo de "reciclagem" e depois disso seriam alocados em outras feiras -livres da cidade. Mais tarde soube por informantes da Feira-Livre da Epatur das dificuldades que estes vendedores estavam tendo para adaptarem-se a dinâmica da feira-livre.

${ }^{10}$ Referência às formas de vendas de doces e outras mercadorias das "pretas minas" que encontramos em crônicas e relatos sobre a cidade e o próprio largo do mercado em "tempos idos".
} 
serem tratados ao longo do texto. O que é importante situar neste momento é que este contexto do mercado de rua leva o pesquisador a redescobrir seu fazer etnográfico, adaptando-se aos diferentes desafios que a situação social impõe ${ }^{11}$, elaborando outras estratégias de "estar em campo".

Mesmo assim, a própria tentativa de realizar tal caminhada pelo espaço do mercado de rua se constitui como um dado de campo, evidenciando as diferentes formas de apropriação deste lugar por vendedores e consumidores. Enquanto muitas pessoas caminhavam rapidamente atravessando o largo de um lado a outro, procurei "mapear" as diferentes bancas - podia ver que não eram muitas, no máximo umas vinte - e os tipos de produtos que estavam sendo vendidos. Algumas delas chamavam mais a atenção do que outras: um senhor vendia rúculas e atros verdes sobre duas caixas com uma folha de madeira em cima, estava mais distanciado dos outros vendedores, poucas mercadorias estavam em seu tabuleiro; uma senhora, toda vestida de cor de rosa, arrumada, vendia mamão e abacaxi em uma banca que tinha tapumes sobre caixas. Ainda duas outras bancas impressionavam pelo tamanho e variedade de frutas: uma delas tinha uma disposição dos produtos que ia do chão até mais ou menos a altura dos olhos, como se seguisse o caminho de uma escada ou arquibancada, não se via a estrutura que sustentava os produtos; a outra banca não passava de uns 50 centímetros do chão, mas ocupava um grande espaço e em um lugar de muita circulação, praticamente uma esquina que levava ao terminal de ônibus.

$\mathrm{Na}$ confluência destas imagens as "artes do fraco"12 ganhavam corpo. A improvisação do espaço das vendas com caixas e pedaços de madeira apontavam para os usos da "sucata" vistas por De Certeau como "desvios" ou "dissimulações" na ordem econômica vigente. Seguindo em uma análise das práticas cotidianas de uma cultura popular, a partir de M. de Certeau, a emergência deste tipo de atividade no largo do mercado caracteriza-se por "golpes no terreno da ordem estabelecida", procurando maneiras de escapar a lógica disjuntiva das especializações do trabalho e do desemprego. Estes golpes ou táticas do popular constituem-se como uma arte.

\footnotetext{
${ }^{11}$ No caso da etnografia que venho realizando no mercado de rua, um dos limites que se impõe é a possibilidade de registro da paisagem sonora do local, tendo em vista o constante e intenso fluxo de pessoas pelo mercado, o que dificulta até mesmo a construção de um espaço de observação, um ponto onde se possa "ficar". Neste caso, só a partir de muitos retornos a campo parece possível a construção de uma relação de maior proximidade com os informantes a ponto de realizar uma primeira gravação.

${ }^{12}$ CERTEAU, Michel de. A Invenção do Cotidiano - 1: Artes de Fazer. Petrópolis, Vozes, 1994.
} 
A criatividade destes golpes apresentava-se também na apropriação da dispersão característica do espaço do largo, pois a disposição das bancas que pareciam um tanto quanto aleatórias, acabavam "conduzindo" os passantes, "quase" formando um corredor de bancas umas na frente das outras. $\mathrm{O}$ uso do "quase" justifica-se pelo caráter movente destas bancas, já que repentinamente uma banca se transformava em duas, modificando a configuração das vendas, sem que pudéssemos ver de onde saia a mercadoria. Neste caso, o que parece arbitrário e caótico na construção deste espaço de vendas é a expressão de sua característica principal, ou seja, a constante transformação, que se dá de acordo com as possibilidades de venda.

Além desta apropriação "física" do espaço do largo para as vendas ao rés do chão, a disputa pelo "espaço sonoro" também é constante e muito mais acirrada do que podia ser observado na feira-livre. A ambiência sonora do Largo Glênio Peres tem uma consistência, uma massa, a cacofonia da vida urbana é quase palpável. Os atos de falas e anúncios dos vendedores são misturados, mixados, com inúmeros outros sons e ruídos que conformam a musicalidade do largo. Estes sons parecem conduzir o ritmo dos acontecimentos cotidianos. Assim, junto ao shopping de fábrica situado na esquina do largo que volta suas caixas de som para o lado de fora atraindo possíveis clientes, ao terminal de ônibus, na outra esquina, com ruídos fortes e ininterruptos de motores, aos camelôs um pouco mais adiante e também todos os passantes e suas conversas entrecortadas estão os vendedores do mercado de rua.

\section{O PACOTÃO DA LARANJA É UM REAAL!}

\section{BONITO PIMENTÃO PACOTE A UM REAAL!}

\section{OLHA O ABACAXI A UM REAAL!}

\section{É UM REAL O PACOTE DA MAÇÃã ! DOZE MAÇÃ A UM REAAL!}

Se na feira-livre toda a sonoridade tem como plano principal a voz dos feirantes em suas piadas e jogos de palavras, isolando as sonoridades da cidade como o trânsito, no largo a "densidade" do som pede uma atenção redobrada a escuta para que se possa minimamente identificar os diferentes elementos. Música urbana, a enunciação dos vendedores já conta com estes ruídos e por isso a elaboração de diferentes entonações 
de voz para o anúncio dos produtos é muito estudada. Os jogos de palavras que fazem parte deste espaço já não se dirigem tanto ao freguês, através de brincadeiras e metáforas com o alimento, mas buscam enfatizar a apresentação do produto a ser vendido. Estes anúncios parecem destinados a um "comprador genérico" caracterizando-se pela repetição constante e pelo entrelaçamento entre as falas, que parecem não capturar o comprador através das metáforas alimentares e sim a partir do preço e quantidade, mas que no fundo apresentam um tom hipnótico.

Em meio a esta agitação do cotidiano, as táticas de vendas acionadas no mercado assumem uma performatividade representada na expressão comunicativa ${ }^{13}$ da voz que busca enfatizar as vantagens da compra daqueles alimentos por um valor tão irrisório. Retomando as idéias de M. de Certeau sobre as táticas e golpes em relação a uma ordem estabelecida como práticas que se transformam em saber, é possível estabelecer uma ligação com a concepção de L. Sullivan ${ }^{14}$ da performance como autoconstitutiva, ou seja, como um conhecimento que se constrói em ato, o que remete a construção destes personagens de vendedores na sua própria prática cotidiana no largo. A performatividade destes atores está colocada nas suas táticas de venda, de conformar o espaço, nas suas formas de agenciar os diferentes elementos de sua informalidade, pois esta improvisação pressupõe o conhecimento de determinados códigos que orientam das trocas comerciais na cidade, bem como do uso do espaço público.

\section{$O$ contexto efêmero das vendas}

Neste burburinho, o comércio de alimentos e os atos de compra e venda no mercado de rua do Largo se dão de maneira muito direta e rápida e, portanto, são atos a que parecem estar incorporados outros sentidos e outros valores, diferente do que chamei na dissertação de mestrado de "artes de nutrir". A partir das descrições acima é possível imaginar a confusão em que estas vendas acontecem: em meio ao fluxo pessoas que atravessam o Largo no final da tarde, na partilha do espaço físico com outros

\footnotetext{
13 BAUMAN, R. \& BRIGGS, C. Poetics and performance as critical perspectives on language and social life. In: Anual review of Anthropology, 19:59-88, 1990. GOFFMAN, Erving. Footing. \& GUMPERZ, J. Convenções de Contextualização. In: Sociolingüística Interacional: antropologia, lingüística $e$ sociologia em análise de discurso. Branca Telles Ribeiro e Pedro m. Garcez (orgs), Editora AGE, Porto Alegre, 1998.

${ }^{14}$ SULLIVAN, Lawrence. Sounds and Senses: toward a hermeneutics of performance. In: History of Religions. Chicago University Press, 1986.
} 
eventos, na disputa do espaço sonoro com os ruídos urbanos. Em um primeiro momento é difícil identificar quem são os vendedores e mais complicado ainda perceber alguém comprando. As vendas parecem acontecer muito rapidamente, pois a um descuido do olhar já se perde o comprador de vista. Por outro lado, os vendedores não despendem muito tempo com um cliente apenas, atendendo-os rapidamente quase que decidindo qual a fruta que ele deve levar. Mas a uma razão por trás de toda esta agilidade e que se refere à qualidade dos alimentos que são vendidos ali.

Como disse antes, o principal mote destas vendas é o preço. Quase tudo é vendido a um real. Um abacaxi por um real, três abacates por um real, um mamão por um real, o pacotão da batata a um real, 12 laranjas a um real, o pacote da maçã a um real, o pimentão colorido pacote a um real e assim por diante. Os únicos dois produtos que estavam sendo vendidos por mais de um real eram uvas e ameixas. Mas há uma razão especifica para um preço tão baixo: as frutas a venda estavam em sua maioria já muito maduras, algumas verdadeiramente estragadas. Caminhando pelo mercado, olhando e escolhendo frutas como se fosse compradora, via que o mercado de rua era a última possibilidade de consumo, se não fossem vendidos para um uso imediato, dali aqueles alimentos só poderiam ir para o lixo. Nas suas táticas de venda, destinadas certamente para as classes populares, os vendedores atribuíam utilidades para as frutas que já haviam "passado do ponto": "esse abacaxi tá ótimo para fazer suco, olha só senhora”! Um abacaxi a um real não é possível escolher muito. Esta é a lógica das relações de compra e venda no mercado do largo, as frutas são baratas e sempre podem ser resignificadas em suas utilidades, pode-se fazer suco, salada, etc. Neste jogo social as relações são efêmeras, rapidamente o cliente chega até a banca, escolhe uma das frutas, estende um real para o vendedor que continua gritando o preço dos produtos e sai. Em geral, os vendedores ficam circulando em volta de seus tabuleiros, trocando de lugar uns com os outros, fazendo os pacotes dos produtos a serem vendidos, parecendo acompanhar a movimentação do largo, como se estivessem em uma fábrica de montagem. Formas de manter a estética da movencia que faz parte deste ambiente.

Os tipos de hortifrutigranjeiros oferecidos em cada banca não variavam muito: limão, tomate, cebola, batata, abacaxi, banana, maçã, laranja, mamão, abacate, rúcula, alface, ameixa e uva a maioria vendidos em pacote já fechados. Algumas frutas estavam um pouco mais novas do que outras, mas todas já bem maduras. Numa conversa com um dos vendedores soube a origem da sua mercadoria: eram produtos da CEASA destinados a um grande supermercado de Porto Alegre, mas como este não havia 
comprado, acabou chegando a estes vendedores do mercado de rua. Esta fala é um indício de como estes alimentos chegam até ali, e da característica mutável das bancas, ou seja, vende-se o que estiver disponível.

A "emergência da performance" está justamente na construção desta fluidez e efemeridade das compras, nos repertórios de esquemas de ação que conduzem o comércio, na dinamicidade de usar o espaço do largo para as vendas. Trata-se do espaço da rua inserido na dinâmica econômica da cidade, dando destino aos alimentos que ainda não foram comprados e ao mesmo tempo tornando-os acessíveis a camadas populares da cidade. Esta ação criativa dos vendedores conformando um mercado de rua configura uma poética da cidade, compondo-se de ruídos e odores peculiares.

"A poética urbana se justifica tanto por uma dimensão ética como por uma dimensão estética. Estética, ela nos parece mais frutuosa, para um bom regime de imaginação, de insistir sobre o vai e vem, sobre os acordos da cidade e dos homens. É encontrar uma criatividade, uma beleza, de que somos testemunho e que temos a tendência a relegar ao domínio do rural, como se as cidades não fossem, a sua maneira, uma expressão da Natureza. Ética: os homens não são consciências isoladas, eles comunicam através de suas obras, mas também através de certos lugares, mas também a partir desta Natureza da qual eles provêm"15.

\section{Algumas considerações}

O caráter ensaístico deste texto representa idéias ainda em construção. Relacionar teorias da performance com as questões referentes a uma antropologia urbana voltada para as ações do cotidiano - do ordinário e não extraordinário - exige um exercício de relativização das próprias teorias em questão. Neste caso, um ensaio é uma primeira articulação de pensamentos que buscam alguma ordenação, alguma construção de sentido.

Por outro lado, o fazer etnográfico na cidade e sua demanda de um "estranhamento do familiar" tem nos estudos de performance uma importante fonte de reflexão sobre a "atuação" do antropólogo em campo, suas formas de se relacionar com o informante e de dar atenção para as sutilezas e nuances da situação etnográfica que podem tornar a análise cada vez mais complexa. No caso deste ensaio, trata-se de uma

${ }^{15}$ SANSOT, Pierre. Poétique de la Ville. Paris, Meridiens Klincksiek, 1988. p. 419 
pesquisa de campo inicial na qual estas questões estão sendo levadas em conta a todo o momento. Em termos de uma performance do antropólogo em campo, o mercado de rua do Largo Glênio Peres apresenta grandes desafios, justamente pela dinamicidade das relações, pela intensidade da vida cotidiana ali presente.

Penso que as vendas que se consolidam no largo do mercado possuem um caráter de agência e performatividade que permitem que elas continuem ocorrendo neste espaço, sem serem subsumidas por outros eventos e pelo próprio mercado público. Em termos de uma construção cênica, esta ambiência do largo rende muitas reflexões no que tange uma estética urbana. No entanto, para uma dimensão de experiência estética, ainda são necessários os relatos, as histórias e as interpretações dos próprios vendedores - e quem sabe alguns compradores - e as suas construções de sentido para as "táticas e golpes" que acionam cotidianamente nas vendas de alimentos no largo.

\section{REFERÊNCIAS}

ARANTES, Antônio A. Paisagens Paulistanas: transformações do espaço público. Campinas, SP:Editora da Unicamp: São Paulo: Imprensa Oficial, 2000.

BAUMAN, R. \& BRIGGS, C. Poetics and performance as critical perspectives on language and social life. In: Anual review of Anthropology, 19:59-88, 1990.

CERTEAU, Michel de. A Invenção do Cotidiano - 1: Artes de Fazer. Petrópolis, Vozes, 1994.

CONQUERGOOD, Dwight. Performance Studies: interventions and radical research. In: The Performance Studies Reader, BIAL, Henry (org), London: Routledge, 2004.

ECKERT, Cornelia e ROCHA, Ana Luiza Carvalho da. "Etnografia de rua: estudo de antropologia urbana". Iluminuras: Série do Banco de Imagens e Efeitos Visuais, número 44. Porto Alegre: BIEV, PPGAS/UFRGS, 2001.

GOFFMAN, Erving. Footing. In: Sociolingüistica Interacional: antropologia, lingüística e sociologia em análise de discurso. Branca Telles Ribeiro e Pedro m. Garcez (orgs), Editora AGE, Porto Alegre, 1998.

GUMPERZ, J. Convenções de Contextualização. In: Sociolingüística Interacional: antropologia, lingüística e sociologia em análise de discurso. Branca Telles Ribeiro e Pedro m. Garcez (orgs), Editora AGE, Porto Alegre, 1998.

KAPFERER, Bruce. Performance and the structuring of meaning and experience. In: Anthropology of Experience. Turner, V. \& Bruner, E. eds. Chicago: University of Illinois Press, 1986.

LANGDON, Jean. A Fixação da Narrativa: do mito para a poética de literatura oral. In: ECKERT e ROCHA (Org.). Revista Horizontes Antropológicos 12. Porto Alegre: UFRGS, 1999.

MOLES, Abraham e RHOMER, Elisabeth. Labyrinthes du Vécu. L'espace: matière d'actions. Paris, Librairie des Meridiens, 1982.

MORRIS, Rosalind. All made up: performance theory and the new anthropology of sex and gender. IN: Annual Review of Anthropology, 1995. BUTLER, Judith. Performative acts and gender constitutions: an essay in phenomenology and feminist theory. In: Bial, H. The Performnce Studies Reader. London: Routledge. 
SANSOT, Pierre. Poétique de la Ville. Paris, Meridiens Klincksiek, 1988.

SULLIVAN, Lawrence. Sounds and Senses: toward a hermeneutics of performance. In: History of Religions. Chicago University Press, 1986.

VELHO, Gilberto. Projeto e Metamorfose: antropologia das sociedades complexas. Rio de janeiro, Ed. Jorge Zahar, 1999. 